\title{
Análise das condições de conforto térmico da cidade de Vitória, ES
}

\section{Analysis of the thermal comfort conditions of the city of Vitória, ES}

\author{
Tatiana Camello Xavier ${ }^{* 1} \bowtie(D)$, Wemerson Diascanio Oliveira ${ }^{2} \bowtie(D$, \\ Edson Soares Fialho ${ }^{3} \otimes$ (iD)
}

\author{
${ }^{1}$ Instituto Federal do Espírito Santo, Cariacica, Espírito Santo, Brasil e Universidade Federal do \\ Espírito Santo, Vitória, Espírito Santos, Brasil \\ 2Universidade Federal do Espírito Santo, Vitória, Espírito Santo, Brasil \\ 3Universidade Federal do Espírito Santo, Vitória, Espírito Santo, Brasil e Universidade Federal de \\ Viçosa, Viçosa, Minas Gerais, Brasil \\ E-mail: wemersonoliveira.geo@gmail.com (WDO); fialho@ufv.br (ESF) \\ *E-mail para correspondência: tatianacamello@yahoo.com.br
}

\author{
Recebido (Received): 16/07/2020 \\ Aceito (Accepted): 24/02/2021
}

Resumo: A conformação do espaço urbano apresenta grande influência no microclima local e, consequentemente, no conforto térmico da população. As transformações do ambiente urbano ocasionam alterações da superfície natural, assim como do albedo e do balanço da radiação, gerando grandes impactos para o meio. O objetivo deste estudo foi avaliar a evolução das condições de conforto térmico da cidade de Vitória, ES, relacionando o comportamento do clima e a evolução urbana, a partir das médias mensais das normais climatológicas do banco de dados do Instituto Nacional de Meteorologia (INMET) abrangendo no total o período de 1931 a 2010. Para essa avaliação foi definido o índice de Temperatura Efetiva (TE) utilizando para o cálculo da sensação térmica as variáveis temperatura e umidade relativa do ar. Os resultados mostraram que ao longo dos anos, com o avanço da urbanização, tanto a temperatura do ar está aumentando quanto, consequentemente, a sensação de desconforto térmico, demandando um maior esforço do sistema termorregulador da população para preservar a temperatura interna do corpo. A temperatura aumentou $0,6^{\circ} \mathrm{C}$ em média entre os períodos, chegando a uma máxima de $1,6^{\circ} \mathrm{C}$ de diferença no mês de abril comparando os períodos de 1931-1960 e 1981-2010 e, como resultado, ocasionando uma variação na sensação de conforto de $1,3^{\circ} \mathrm{C}$.

Palavras-chave: Índice de Temperatura Efetiva; Urbanização; Sensação térmica.

Abstract: The conformation of the urban space has a great influence on the local microclimate and, consequently, on the thermal comfort of the population. The changes in the urban environment cause effects in the natural surface, as well as in the albedo and radiation balance, generating major impacts on the environment. The objective of this study is to evaluate the evolution of thermal comfort conditions in Vitoria, capital city of ES, relating the behavior of the climate and the urban evolution, from the monthly averages of the climatological normals from the National Institute of Meteorology (INMET) database, covering the entire period from 1931 to 2010. The Effective Temperature index (TE) was defined for this evaluation. The variables of temperature and relative humidity of the air were used to calculate the thermal sensation. The results showed that over the years, with the advance of urbanization, the temperature of the air is increasing and, consequently, the sensation of thermal discomfort, demanding a greater effort from the population's thermoregulatory system to preserve the body's internal temperature. The temperature increased $0,6^{\circ} \mathrm{C}$ on average between the consecutive periods, reaching a maximum difference of $1,6^{\circ} \mathrm{C}$ in the month of April comparing the periods of 1931-1960 and 1981-2010 and causing a variation in 1,3 ${ }^{\circ} \mathrm{C}$ comfort sensation as a result.

Keywords: Effective Temperature Index; Urbanization; Thermal Sensation. 


\section{Introdução}

A expansão das malhas urbanas das cidades brasileiras, após o processo de redemocratização, no final da década de 1980, conforme Rolnik e Klink (2011), possibilitou o aumento do mercado interno, sinal de crescimento econômico, que ocasionou uma maior disponibilidade de subsídios públicos ao crédito para a produção habitacional. Porém, apesar do sucesso da política econômica, que influenciou, consequentemente, o crescimento das áreas urbanas, é possível verificar ainda nos dias de hoje que alguns aspectos ainda não foram vencidos, como a concentração de renda, a segregação social e as questões ambientais. Estes levam a cidade se tornar um organismo vivo muito doente, segundo avaliação de Minc (2001), pois a cidade ao drenar recursos e populações produz espaços congestionados e desertos demográficos, resultado do êxodo rural, além de áreas decadentes e desarticuladas. Tal afirmativa, em certa medida, pode ser ampliada para cidades de pequeno e médio porte.

A segregação social, que leva a uma decorrente segregação ambiental, é uma das faces mais importantes da exclusão social. A dificuldade de acesso aos serviços e infraestrutura soma-se a menos oportunidades de profissionalização, maior exposição à violência, discriminação racial, discriminação contra mulheres e crianças, difícil acesso à justiça oficial, difícil acesso ao lazer (MARICATO, 2002).

O clima da baixa atmosfera (troposfera) sob influência das cidades, em certa medida, começa a modificar a relação de entrada e saída de energia no sistema (OKE, 1987). As transformações do meio natural podem gerar mudanças no comportamento dos elementos climáticos em escala local, resultantes das alterações nos balanços de energia, massa e movimento, provocados pelas mudanças na estrutura e dinâmicas das áreas urbanas (LANDSBERG, 1981). Esse ambiente urbanizado, por sua vez, pode gerar um clima urbano, que segundo Monteiro (2015) é entendido como "um sistema que abrange o clima de dado espaço terrestre e sua urbanização".

O crescimento das cidades trouxe consigo uma série de desafios, tanto de ordem socioeconômica, quanto de caráter ambiental. As condições climáticas desreguladas do meio urbano afetam diretamente a qualidade de vida da população (LAMBERTS et al., 1997), podendo impactar negativamente a saúde humana e gerar desconforto na população citadina. (GIGUÈRE, 2009; SOUZA; NERY, 2012; ROUX, 2014).

Golany (1996) já ressaltava que a prática do desenho urbano praticamente não considerava as questões ambientais. Nesta esteira, diversos autores destacaram a importância da aplicação da climatologia no planejamento das áreas urbanas ajustando modelos urbanos e arquitetônicos tradicionais (GOLANY, 1996; GIVONI, 1998; MILLS, 1999; BRAGA, 2019). É primordial permitir que as áreas urbanas continuem crescendo, mas dispondo de novas estratégias para que isso ocorra buscando um ambiente equilibrado para a população, ou seja, repensar os métodos de planejamento da cidade (DUARTE, 2000; BARATA et al., 2020). Dessa forma, Braga (2019) evidencia o importante papel do Plano Diretor da cidade nesse processo. De acordo com Back e Oliveira (2010), estudos que busquem estratégias para minimizar os impactos negativos do crescimento das cidades se tornam cada vez mais latentes, visto que alguns modelos climáticos globais indicam um acréscimo de até $4,0^{\circ} \mathrm{C}$ na temperatura média do planeta.

O papel multidimensional que a cidade desempenha na história das mudanças climáticas é destacado por Blake et al. (2011). As cidades podem ser responsabilizadas por até $40,0 \%$ do total das emissões de gases do efeito estufa em todo o mundo devido a áreas com alta densidade populacional e atividades econômicas. Porém, as cidades podem desempenhar função primordial no desenvolvimento de estratégias de mitigação e de adaptação às mudanças climáticas através de informação e inovação tecnológica. Em uma análise feita com doze grandes cidades do mundo, sete cidades apresentaram tendência significativa de aquecimento, com destaque para São Paulo que atingiu a maior tendência no século passado, identificando o acréscimo de $0,27^{\circ} \mathrm{C}$ por década (BLAKE et al., 2011).

A produção do clima urbano pelas ações humanas sobre a natureza está intimamente ligada à obtenção de condições distintas de conforto e desconforto térmico, entre outros impactos ambientais (LOMBARDO, 1985). As condições de conforto no ambiente externo são parâmetros primordiais para avaliar o microclima e indicar diretrizes para o desenvolvimento urbano sustentável (COCCOLO et al., 2016). Durante as trocas de calor entre o corpo humano e o ambiente, para que o homem esteja em um estado de conforto térmico, o seu organismo não deve estar ganhando ou perdendo mais calor do que o essencial para manter sua temperatura interna na ordem de $37,0^{\circ} \mathrm{C}$, ou seja, a sua homeotermia, não devendo produzir nenhum esforço adicional para isso (FROTA; SCHIFFER, 2003). Portanto, a sensação de conforto térmico do homem vai depender do grau de esforço que o sistema termorregulador fará para manter a temperatura interna do corpo (LAMBERTS, 2011).

De acordo com Frota e Schiffer (2003), as principais variáveis relacionadas à sensação de conforto térmico do ser humano são temperatura, umidade e velocidade do ar e radiação solar incidente, tendo em 
vista que as mesmas apresentam forte relação com o regime de chuvas, a vegetação existente, a permeabilidade do solo e a topografia, por exemplo, além das características antrópicas.

Essa preocupação tem aumentado, tanto assim, que vários trabalhos têm objetivado o estudo do conforto térmico urbano, conceito que expressa a satisfação do corpo humano em relação às condições climáticas do ambiente. Este tipo de estudo configura-se como importante, pois influencia na qualidade ambiental urbana, sendo um parâmetro urbano, e juntamente com outras variáveis biológico-fisiológicas e psicológicas, integra um conjunto de indicadores que definem um conforto ambiental. Desse modo, torna-se um elemento chave na compreensão dos processos urbanos e dos problemas deles decorrentes (PAIVA, 2010).

Diversos trabalhos desenvolvidos em torno do conforto térmico geraram várias tabelas e modelos sobre a influência térmica nos seres humanos e de análise ambiental/climática no Brasil. É o caso da Temperatura Efetiva de Thom (1959), Temperatura Efetiva de Yaglou ou Houghten; Diagrama do Conforto Humano (INMET); Carta Bioclimática de Olgyay; Índice de Conforto Equatorial de Webb; e a Carta Bioclimática de Giovani (1969). Para que seja possível quantificar o comportamento humano diante de um ambiente com suas variáveis específicas é necessário estabelecer critérios e valores limites, de acordo com índices e escalas de conforto térmico, de modo a apresentar a relação entre causa e efeito.

Neste sentido, o objetivo deste trabalho consistiu em uma análise a respeito da condição de conforto térmico da população urbana da cidade de Vitória - ES, a partir da aplicação do índice de Temperatura Efetiva (TE) ao longo de oitenta anos, utilizando dados das Normais Climatológicas do Instituto Nacional de Meteorologia (INMET) e avaliando as características geourbanas e geoecológicas da capital capixaba.

\section{Metodologia}

\subsection{Caracterização da área de estudo}

O município de Vitória trata-se da capital do Estado do Espírito Santo e possui uma área de $98.194 \mathrm{~km}^{2}$, sendo formada por uma porção continental e um arquipélago de 33 ilhas. A capital capixaba limita-se ao norte, oeste e sul, respectivamente com os municípios metropolitanos de Serra, Cariacica e Vila Velha. A oeste é limitada pelo oceano Atlântico. Constitui-se como o centro econômico, financeiro e político da Região Metropolitana da Grande Vitória (RMGV) e do estado do Espírito Santo. O município de Vitória (Figura 1) apresenta população absoluta de cerca de 330 mil habitantes, e densidade demográfica de 3.527 $\mathrm{hab} / \mathrm{km}^{2}$ (PMV, 2020a).

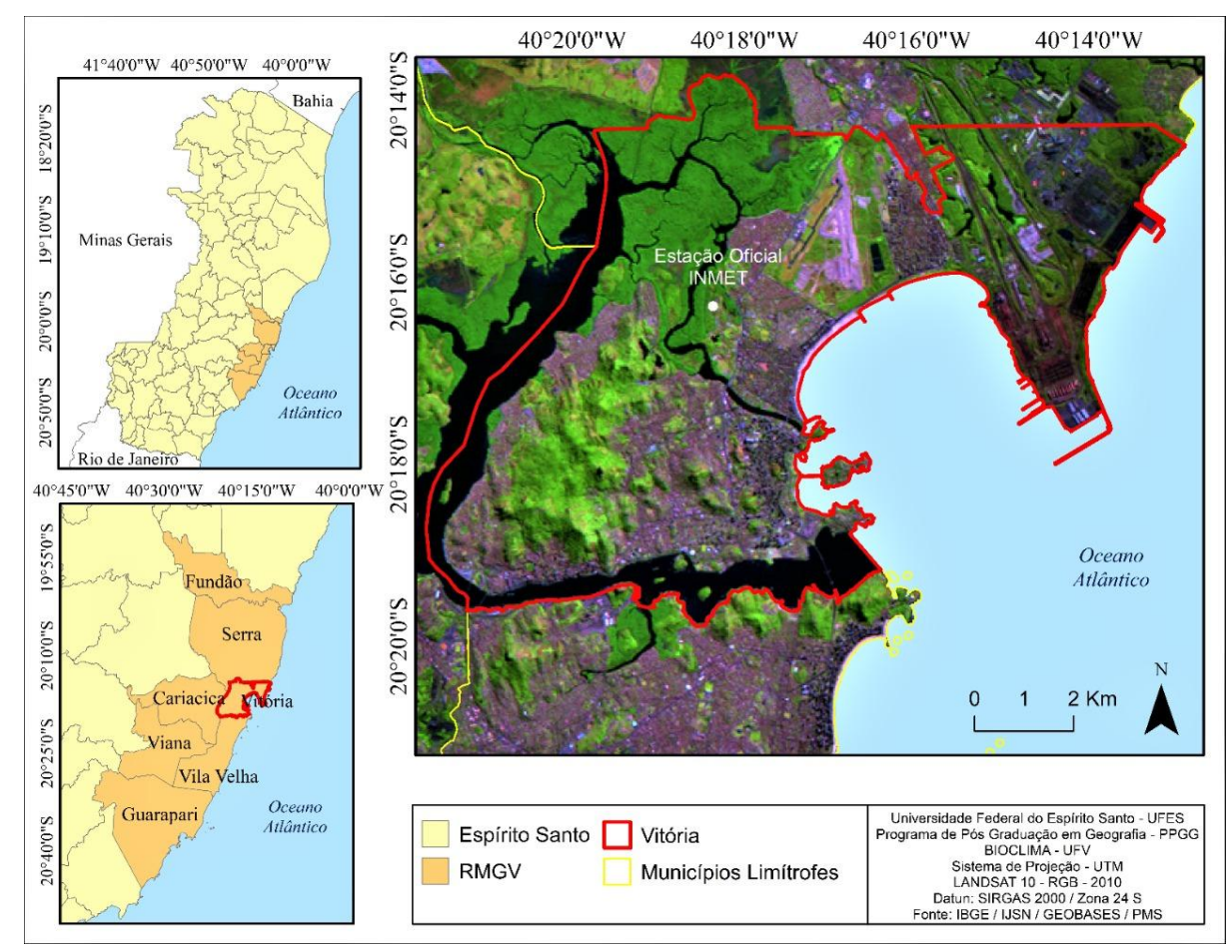

Figura 1: Mapa de localização do município de Vitória no Brasil. Fonte: IBGE (2020). 
De acordo com a classificação de Köppen, o clima de Vitória caracteriza-se como tropical úmido, quente e úmido (KOTTEK et al., 2006). O verão é o período mais chuvoso e apresenta temperatura média de $34,4^{\circ} \mathrm{C}$. No inverno, apesar de não haver secas, os índices pluviométricos reduzem, e as temperaturas giram entorno de $24,4^{\circ} \mathrm{C}$. (PMV, 2020a). Outro importante fator caracterizador das condições climáticas em Vitória é a ocorrência de brisas marítimas e oceânicas. Segundo Gomes (2017), o movimento das brisas influencia na diminuição da amplitude térmica e na amenização das temperaturas máximas.

O município de Vitória apresenta altitudes, variando entre $0 \mathrm{~m}$ nas porções planas do litoral e 300m nas elevações do interior. Esta topografia influencia fortemente na urbanização do município, em que a cidade cresce exprimida entre os maciços e o litoral, além de subir pelas encostas. Como fora constatado por Silva et al. (2012), que a porosidade das edificações, é responsável pela entrada do vento entre as quadras e a rugosidade é capaz de potencializar o efeito canalizador de ruas perpendiculares à orla marítima, resultado corroborado pelos questionários, que apontaram que locais de maior velocidade do vento, há predominância da sensação de neutralidade térmica, enquanto nos pontos com menor ventilação, sensações de leve calor a muito calor.

$\mathrm{Na}$ baia de Vitória observam-se ventos predominantes do quadrante noroeste, sendo essa direção modificada com a atuação de sistemas atmosféricos de larga escala. Entre os principais fenômenos meteorológicos de escala sinótica que influenciam no tempo e no clima da capital capixaba podemos destacar: a Zona de Convergência do Atlântico Sul (ZCAS), Frente Fria (FF) e o Anticiclone Subtropical do Atlântico Sul (ASAS) (SANT’ANNA NETO, 2005; VAREJÃO-SILVA, 2005).

Até o ano de 1900, a ocupação urbana de Vitória ainda era incipiente, sendo o último século o período de maior intensificação do processo de urbanização. Entre os anos de 1900 a 1940 a cidade sofreu um grande aumento de área disponível a partir da execução de diversos projetos de aterros. O projeto conhecido como "Novo Arrabalde", de Saturnino de Brito, ampliou em cinco vezes a área da cidade (PMV, 2020b) (Figuras 2A e 2B).

Nas décadas de 1940 e 1950 houve a ocupação de várias regiões, e os aterros continuaram avançando sobre o mar (Figura 2C). Também aconteceu nesse período a ocupação das encostas do Maciço Central. Como mostra a Figura 2D, na década de 1960 a cidade se expande e a parte continental é ocupada, registrando a ocupação da região de Camburi, onde importantes equipamentos foram instalados, como a Universidade Federal do Espírito Santo (UFES), o Aeroporto e complexo portuário de Tubarão. Além disso, a ocupação das encostas do Maciço Central é intensificada e a cidade ganha mais uma área de aterro (PMV, 2020b).

Entre 1970 e 1980 ocorre a implantação da Siderúrgica Tubarão (CST) (1976) ao lado das instalações da Companhia Vale do Rio Doce (CVRD), intensificando os problemas de poluição atmosférica da cidade. As áreas das instalações da CST e da CVRD ocupam cerca de 1/3 da mancha urbana total do município, como vemos na Figura 2E e Figura 2F. Os projetos de aterros que aconteceram ao longo dos anos em Vitória geraram tantas modificações que chegaram a alterar o contorno da cidade e seu limite com o mar (PMV, 2020b).

Alguns aterros continuaram sendo realizados e a ocupação da região de Camburi e da parte insular do município alcançaram destaque nos anos de 1970 e 1980. Neste período a capital capixaba apresenta um grande crescimento industrial, e com ele um acelerado aumento da urbanização. Neste processo são implementados na cidade uma gama variada de serviços, como: Supermercados, shopping-centers, lojas de departamento, escritórios dos mais diversos, transportes, bancos, serviços do comércio em geral, hotelaria, construtoras/ imóveis comerciais e residenciais, equipamentos de lazer/diversão, etc. (FREIRE, 2004).

A população também apresenta um alto crescimento a partir da década de 1970, no qual o número de residentes no município de Vitória aumentou quase 5 vezes, saltando de 26.448 pessoas na década de 60 para 132.036 pessoas em 70 (Figura 3) (IPEA, 2020). Esse incremento populacional foi fortemente influenciado pelo crescimento industrial da região e a crise na área rural, ocasionando a vinda de muitos trabalhadores rurais atraídos pelas novas oportunidades nos grandes projetos industriais, gerando muitos desempregados e exigindo um novo planejamento espacial com a demanda crescente da população, principalmente na região nordeste da ilha (CASTIGLIONI, 1994; FREITAS, 2004). Nas duas décadas seguintes o aumento não foi tão substancial, porém também foi expressivo, girando entre 24,0\% e 57,0\% esse aumento (IPEA, 2020). 


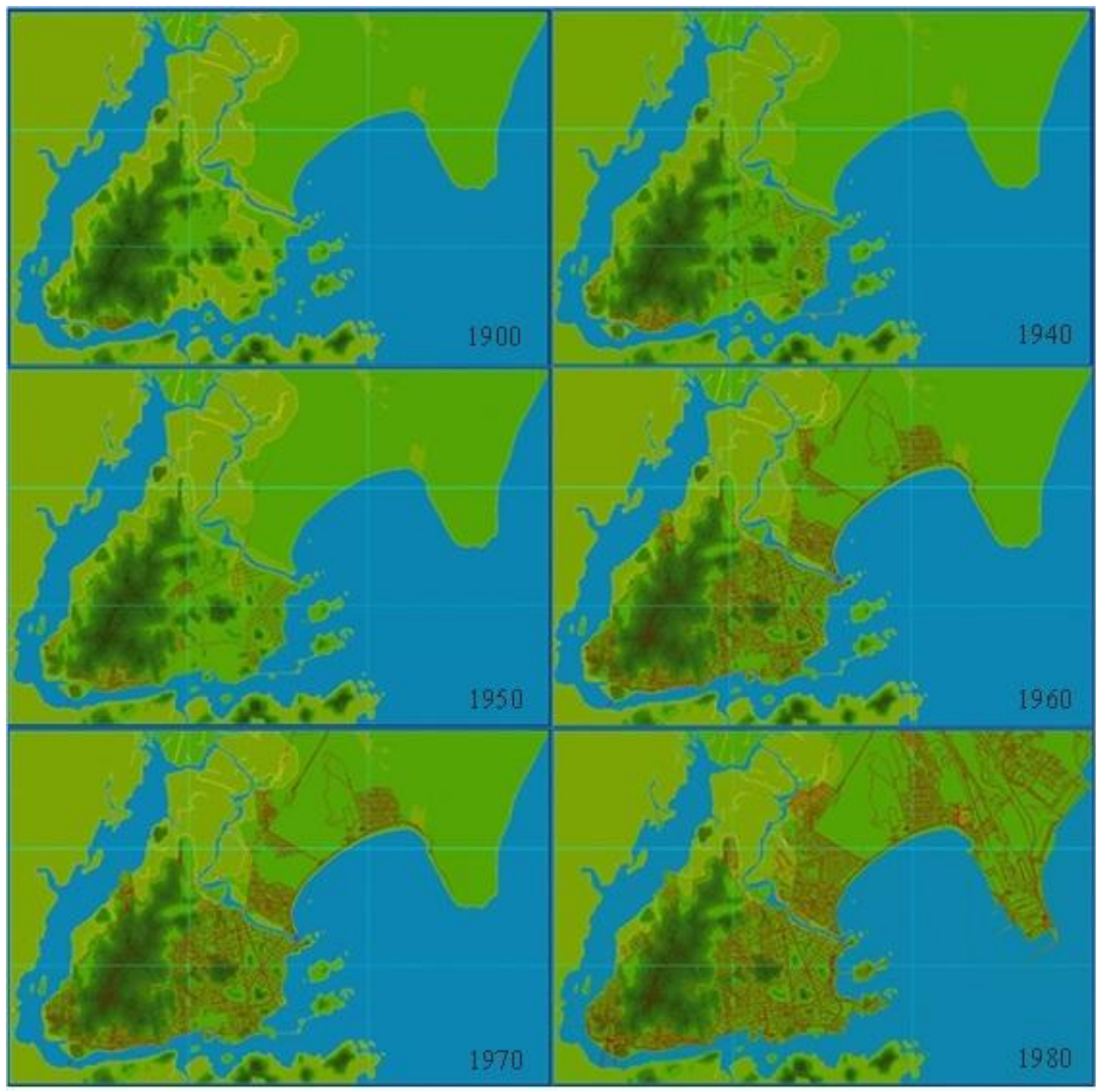

Figura 2: A) Imagem da ocupação urbana de Vitória no ano de 1900. B) Imagem da ocupação urbana de Vitória no ano de 1940. C) Imagem da ocupação urbana de Vitória no ano de 1950. D) Imagem da ocupação urbana de Vitória no ano de 1960. E) Imagem da ocupação urbana de Vitória no ano de 1970. F) Imagem da ocupação urbana de Vitória no ano de 1980. Fonte: Adaptado de PMV (2020c).

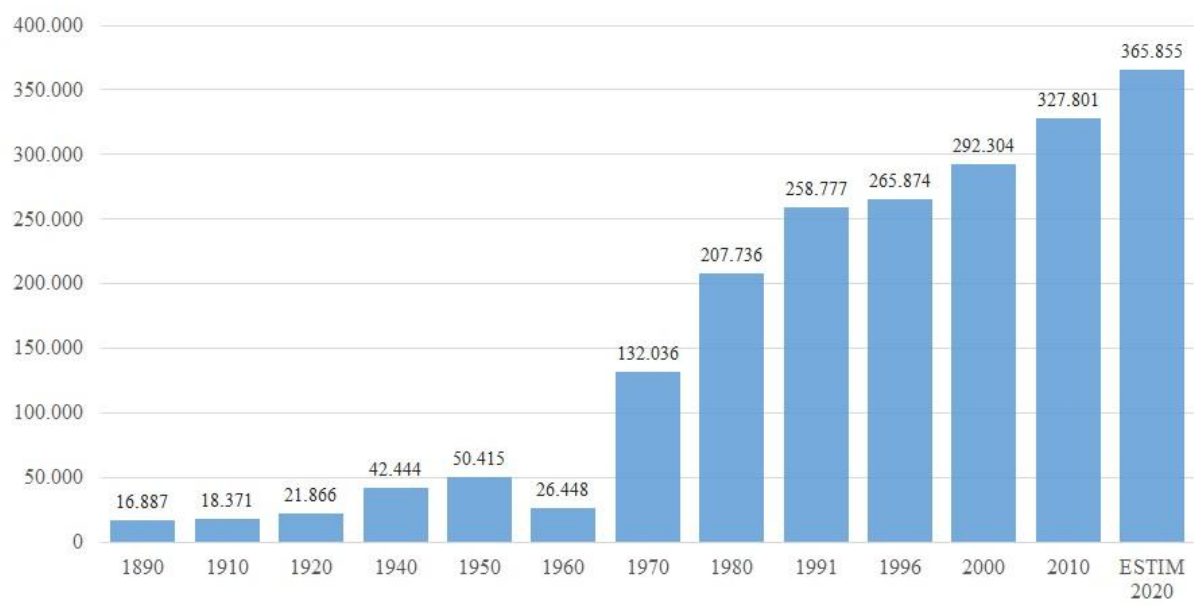

Figura 3: Gráfico do Crescimento Populacional de Vitória de 1890 a 2020. Fonte: Adaptado do Ipea (2020). 
A partir da década de 1990, em decorrência da grande saturação do espaço urbano, a cidade de Vitória iniciou o processo de crescimento vertical, especialmente nos bairros de classe média alta, na faixa da orla, que compreende do Shopping Vitória até o Porto de Tubarão, passando pela praia de Camburi. Contudo, segundo IPES (2005) a transformação do cenário urbano, apresentado ao final da década de 1990. Enquanto em outras cidades brasileiras a produção de edifícios com mais de cinco pavimentos resultou na mera incorporação de novos empreendimentos a malhas urbanas já acentuadamente verticalizadas, na RMGV resultou em uma sensível reestruturação do padrão de ocupação anterior - de predominância horizontal -, conferindo-lhe um perfil vertical próprio das grandes metrópoles (Figuras 4A e 4B).
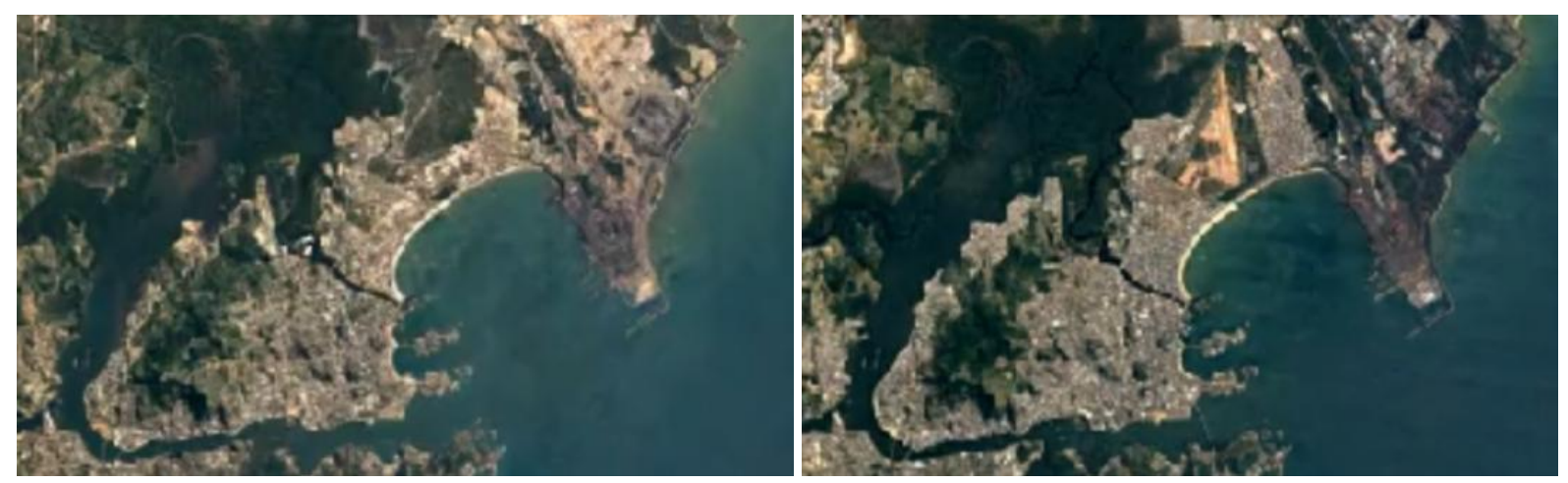

Figura 4: A) Imagem da ocupação urbana de Vitória no ano de 1985. B) Imagem da ocupação urbana de Vitória no ano de 2010. Fonte: Adaptado de Google Earth (2020).

De acordo com Machado et al. (2017), os aterros que aconteceram em Vitória ao longo de 45 anos aumentaram a área da cidade em torno de $10 \%$, sendo que 93,0\% dessa área está completamente urbanizada e comporta aproximadamente $23,0 \%$ do sistema viário, além disso em 2015 , já abrigava quase metade da população.

A partir da observação da expansão da mancha urbana e sua consequente mudança de perfil, não somente no município de Vitória, mas também nos municípios vizinhos que compõem a Grande Vitória, estudos relacionados ao clima urbano começam a surgir, identificando a influência da mudança do uso da terra, principalmente a partir da década de 1990. Utilizando técnicas de observação de séries temporais (CORREA, 2011), monitoramento intra-urbano (CORREA; VALE, 2016), sensoriamento remoto (COELHO, 2013; COELHO; CORREA, 2013; LORENA et al., 2013; JESUS; COELHO, 2015; PAULA, 2015; SILVA et al., 2017) e observação da influência dos sistemas sinóticos (CORREA et al., 2015), vários estudos na cidade de Vitória identificam a forte influência da alteração do uso e cobertura da terra ao decorrer do desenvolvimento da urbanização e a ação antrópica no aumento dos valores de temperatura. Assim como estudos nas cidades vizinhas tanto de Serra (MONTEIRO; COELHO, 2015; OLIVEIRA, 2018; PEREIRA; ROCHA, 2019) quanto de Cariacica (JESUS, 2016), e estudos de modelagem climática na Grande Vitória (CORREA, 2020), corroboram com a interferência do crescimento da malha urbana, dos novos materiais advindos da urbanização e da verticalização no aumento dos valores de temperatura, como também na formação de ilhas de calor. A maioria dos estudos citados ressalta ainda a importância da utilização de técnicas para o conhecimento do comportamento climático da cidade como instrumento primordial para o planejamento urbano.

\subsection{Procedimentos metodológicos}

Para a realização desta pesquisa foram utilizados dados de temperatura do ar e umidade relativa do ar da estação meteorológica convencional de Vitória (código OMM 83648) localizada na Ilha de Santa Maria, fundada em 1923 e mantida pelo Instituto Nacional de Meteorologia (INMET). Os dados coletados a partir do banco do INMET (2020a e 2020b) abrangeram as normais climatológicas dos períodos de 1931 a 1960 , 1961 a 1990 e 1981 a 2010. Essa estação é a única de Vitória que apresenta dados tão antigos.

Após obtenção e organização dos dados das médias mensais dos períodos analisados, foram calculados os valores dos índices de Temperatura Efetiva (TE). Todo esse processo foi executado com auxílio do software Excel 2016, gerando tabelas e gráficos.

O índice de Temperatura Efetiva foi desenvolvido por Missenard (1937). Esse índice considera em seu cálculo as variáveis temperatura e umidade relativa do ar e é dado pela Equação 1: 
Sendo:

$\mathrm{TE}=$ Temperatura Efetiva $\left({ }^{\circ} \mathrm{C}\right)$;

$\mathrm{T}=$ Temperatura do ar $\left({ }^{\circ} \mathrm{C}\right)$;

$\mathrm{UR}=$ Umidade relativa do ar $(\%)$.

A classificação da sensação térmica deste índice é ampla, abrangendo 9 faixas distintas, que vão de muito frio (menor que $13,0^{\circ} \mathrm{C}$ ) a muito quente (maior que $34,0^{\circ} \mathrm{C}$ ), representando também o grau de estresse fisiológico gerado em cada faixa (Tabela 1).

Tabela 1: Distribuição das faixas de conforto para diferentes graus de percepção térmica e suas respostas fisiológicas do índice de Temperatura Efetiva (TE)

\begin{tabular}{cccc}
\hline Faixas & TE $\left({ }^{\circ} \mathbf{C}\right)$ & Sensação Térmica & Grau de estresse fisiológico \\
\hline $\mathbf{1}$ & $<13$ & Muito frio & Extremo estresse ao frio \\
$\mathbf{2}$ & $13 \mid-16$ & Frio & Tiritar \\
$\mathbf{3}$ & $16 \mid-19$ & Frio moderado & Ligeiro resfriamento do corpo \\
$\mathbf{4}$ & $19 \mid-22$ & Ligeiramente frio & Vasoconstricção \\
$\mathbf{5}$ & $22 \mid-25$ & Confortável & Neutralidade térmica \\
$\mathbf{6}$ & $25 \mid-28$ & Ligeiramente quente & Ligeiro suor, vasodilatação \\
$\mathbf{7}$ & $28 \mid-31$ & Quente moderado & Suor \\
$\mathbf{8}$ & $31 \mid-34$ & Quente & Suor em profusão \\
$\mathbf{9}$ & $>34$ & Muito quente & Falha na termorregulação \\
\hline
\end{tabular}

Fonte: Adaptado de Fanger (1972).

A pesquisa utilizou o índice TE por se tratar de um índice eficaz para avaliação de ambientes externos em condições de calor e ser facilmente aplicável em regiões tropicais, conforme afirma Souza e Nery (2012). O Índice de Temperatura Efetiva tem sido utilizado em diversas pesquisas no Brasil e apresentado resultados relevantes. Em avaliação comparativa com outros índices, o TE representou resultados mais confiáveis em relação a situação de Presidente Prudente (FANTE et al., 2017). Em estudo na cidade de São Paulo, o TE se mostrou eficaz para determinar o conforto térmico humano, sendo considerado o mais apropriado para a cidade tanto para avaliações de ambientes externos quanto internos, fornecendo representações adequadas à situação da região (NEDEL et al., 2015).

\section{Resultados e discussão}

A partir dos resultados obtidos foi verificado que as normais climatológicas da estação de Vitória, coletados pelo INMET nos períodos de 1931-1960, 1961-1990 e 1981-2010 indicam valores de temperatura do ar aumentando ao longo do tempo. Em consequência, os valores obtidos para o índice de Temperatura Efetiva também apontam aumento de seus valores em todos os meses do ano (Figura 5).

A temperatura aumentou em média $0,6^{\circ} \mathrm{C}$ em todos os meses a cada período de 30 anos consecutivos avaliados. Comparando o primeiro (1931-1960) e o último (1981-2010) períodos temos uma média mensal de aumento de $1,2^{\circ} \mathrm{C}$, sendo os meses de fevereiro, março, abril e julho os que apresentaram a maior variação ao longo das normais climatológicas. A diferença máxima foi observada no mês de abril $\left(1,6^{\circ} \mathrm{C}\right)$ e a mínima no mês de junho $\left(0,9^{\circ} \mathrm{C}\right)$ (Figura 5).

Tais resultados encontram ressonância em Correa (2011), que ao observar os decênios 1978 a 1987, 1988 a 1997 e 1998 a 2007 no município de Vitória, verificou que os maiores valores de temperaturas foram observados no terceiro decênio (1998 a 2007), sendo assim, este foi o decênio mais quente. Marengo (2011) ressaltou que desde 1995 as cidades brasileiras de Rio de Janeiro, São Paulo, Manaus, Salvador e Cuiabá também apresentaram tendência de aumento da temperatura do ar, e relata que tal fato não se deve somente à variabilidade natural, mas também à interferência antropogênica a partir da urbanização e da industrialização. 


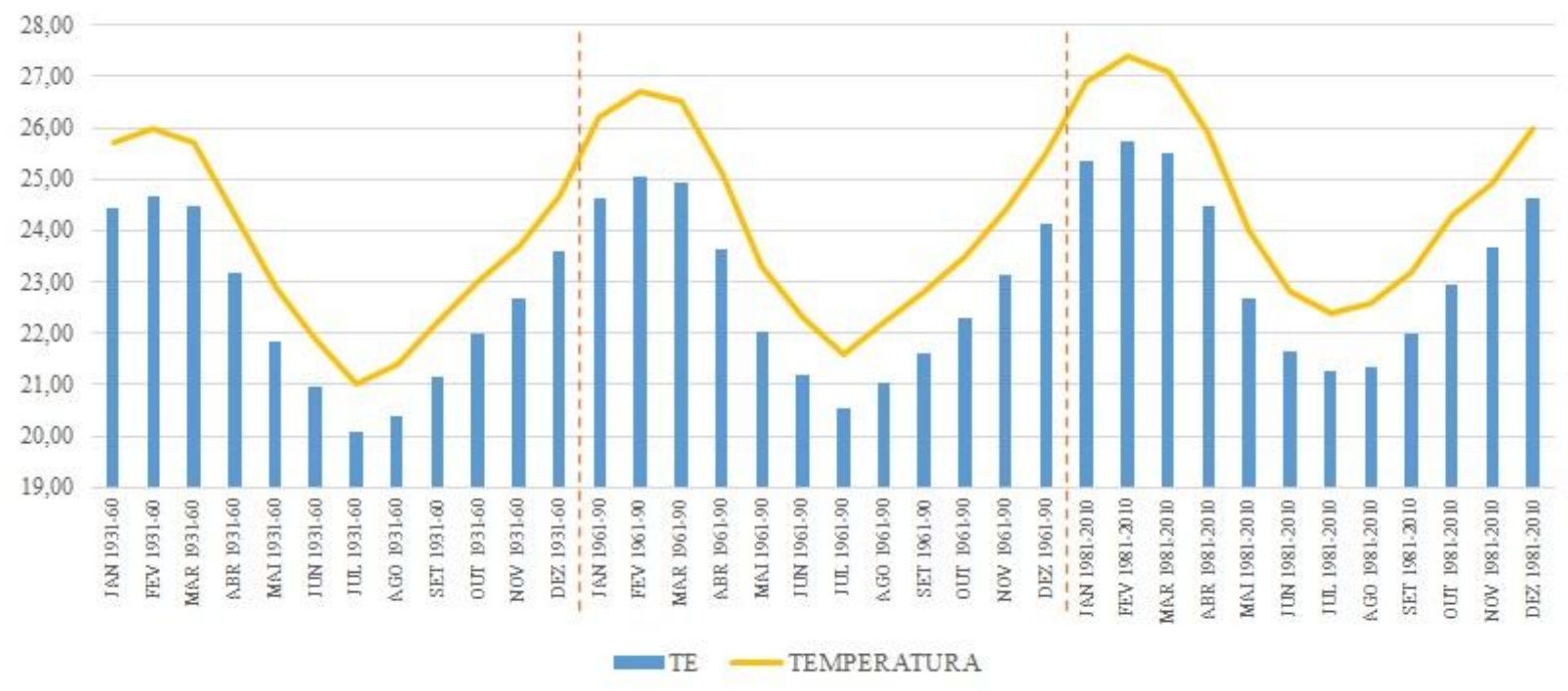

Figura 5: Gráfico do Índice de Temperatura Efetiva e da Temperatura do ar das Normais Climatológicas dos três períodos analisados. Fonte: Adaptado do Inmet (2020a e 2020b) e Autores (2020).

$\mathrm{O}$ índice de Temperatura Efetiva indica, em média, um aumento de $0,6^{\circ} \mathrm{C}$ na sensação térmica em cada mês entre os períodos. Entre 1931-1960 e 1981-2010 a diferença média da sensação térmica alcança um aumento de $0,9^{\circ} \mathrm{C}$, sendo a menor diferença no mês de junho, com elevação de $0,7^{\circ} \mathrm{C}$. A maior diferença foi observada no mês de abril com acréscimo de $1,3^{\circ} \mathrm{C}$ na sensação de conforto térmico (Figura 5).

Também foi possível constatar que a variação sazonal da temperatura do ar durante o ano se mantém característica, demonstrando meses com particularidades mantidas com o passar do tempo. Com isso, o comportamento do índice TE segue o mesmo ritmo, apresentando características próprias de cada mês. Os meses de maio a outubro com as temperaturas e os índices mais baixos, e o período de novembro a abril com valores mais altos.

Aplicando-se o índice TE às médias mensais das Normais Climatológicas da estação de Vitória, foi possível notar que durante todo período avaliado as sensações térmicas encontram-se em três faixas, sendo elas: ligeiramente fresco, confortável e ligeiramente quente (Figura 6).

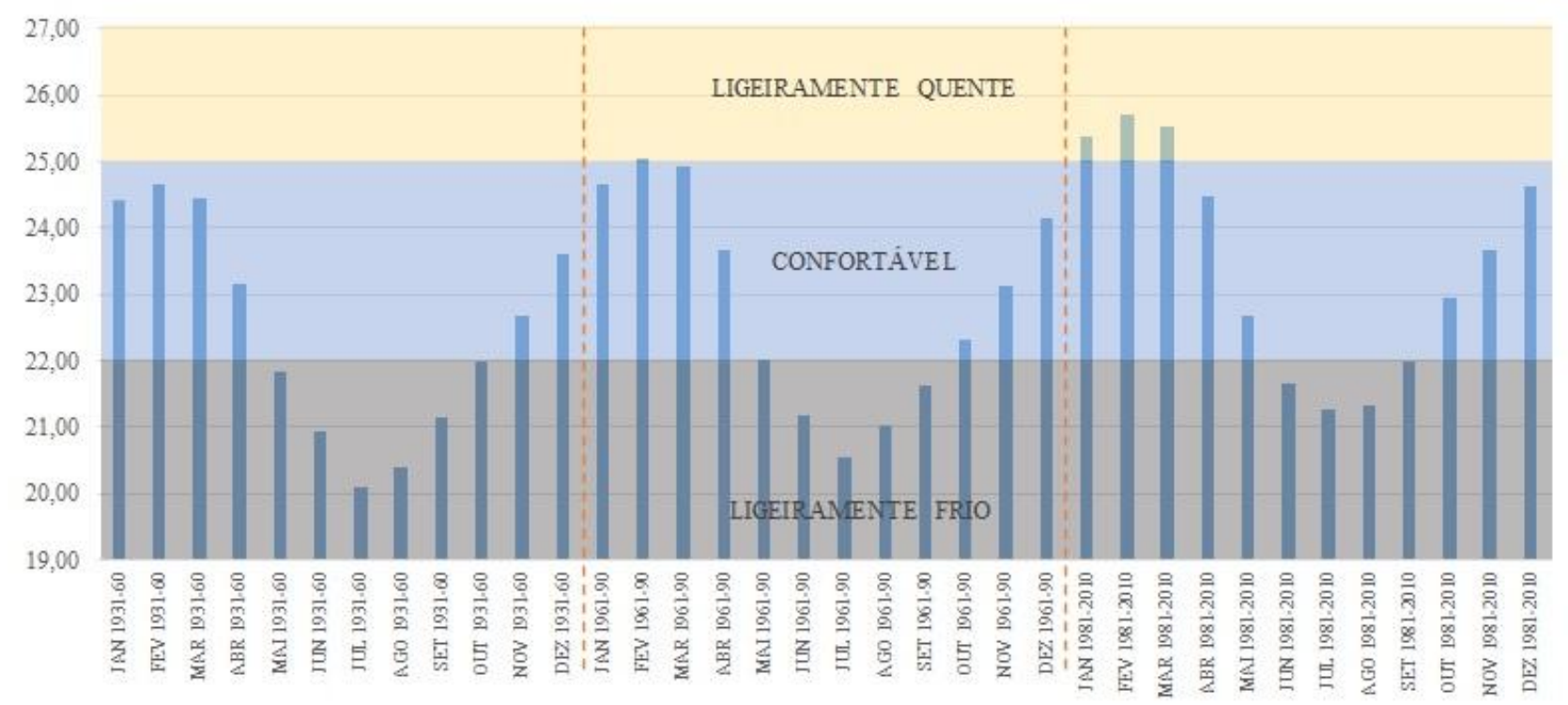

Figura 6: Gráfico do Índice de Temperatura Efetiva (TE) dos três períodos analisados com as faixas de sensação térmica. Fonte: Autores (2020). 
Ao longo dos anos os valores de TE acompanharam o padrão de crescimento da temperatura do ar. Assim, podemos observar que entre a primeira normal climatológica (1931-1960) e a última (1980-2010), quase $50,0 \%$ dos meses mudaram de faixa de conforto térmico, e sempre para uma faixa de conforto acima da anterior.

Os meses de janeiro, fevereiro, março, abril, novembro e dezembro no período de 1931-1960 se encaixavam na faixa de sensação térmica confortável, com valores do TE de 22,0 a $25,0^{\circ} \mathrm{C}$, ou seja, com o grau de estresse fisiológico de neutralidade térmica, não necessitando de nenhum esforço do sistema termorregulador para manter a temperatura interna do corpo.

Porém, no período de 1961-1990, o mês de fevereiro já passou para a faixa de ligeiramente quente e, no período de 1981-2010 janeiro e março também passaram a se enquadrar nessa faixa, já apresentando desconforto térmico e um grau de estresse fisiológico de ligeiro suor e vasodilatação, com sensação térmica entre 25,0 e $27,0^{\circ} \mathrm{C}$.

Já os meses de maio a outubro se encaixavam na faixa de ligeiramente fresco, com sensação térmica de 19,0 a $22,0^{\circ} \mathrm{C}$, no período de 1931-1960, indicando grau de estresse fisiológico de vasoconstricção. A partir do período de 1961-1990, maio e outubro já passaram a se enquadrar na faixa de confortável, apresentando valores de sensação térmica acima de $22,0^{\circ} \mathrm{C}$. Além disso, o mês de setembro revelou o valor de sensação térmica de $21,9^{\circ} \mathrm{C}$ no período de $1981-2010$, isto é, uma diferença mínima para também já se enquadrar em uma faixa acima.

A dinâmica comportamental da umidade ao longo do ano é bem característica e não representou uma variação muito grande entre os períodos. Apenas o período de 1931-1960 se difere um pouco mais dos outros apresentando valores de umidade de 1,5 a 4,2\% acima dos demais. Já a diferença entre os períodos de 1961 1990 e 1981-2010 chega ao máximo de 1,9\% (Figura 7).

As maiores diferenças de conforto térmico foram observadas entre os valores do período 1930-1960 e 1990-2010, sendo percebidas especialmente nos meses quentes e nos meses de abril e julho. O aumento gradativo da TE entre os períodos analisados estão intimamente ligados ao processo de urbanização vivenciado pelo município, uma vez que as alterações da morfologia urbana e das dinâmicas da cidade influenciam na elevação da temperatura do ar, na diminuição da umidade e consequentemente na piora da sensação de conforto térmico.

Além das transformações da cidade, o aumento da temperatura global também é um fator importante a se considerar na análise da piora da sensação de conforto térmico da capital Capixaba. O $5^{\circ}$ Relatório de Avaliação das Mudanças do Clima (AR5), aponta uma mudança média global da temperatura entre os períodos de 1986 a 2005 e 2016 a 2035 , em uma faixa de $0,3^{\circ} \mathrm{C}$ a $0,7^{\circ} \mathrm{C}$ de acréscimo, aquecimento este resultante das emissões antropogênicas e da variabilidade climática natural (IPCC, 2014).

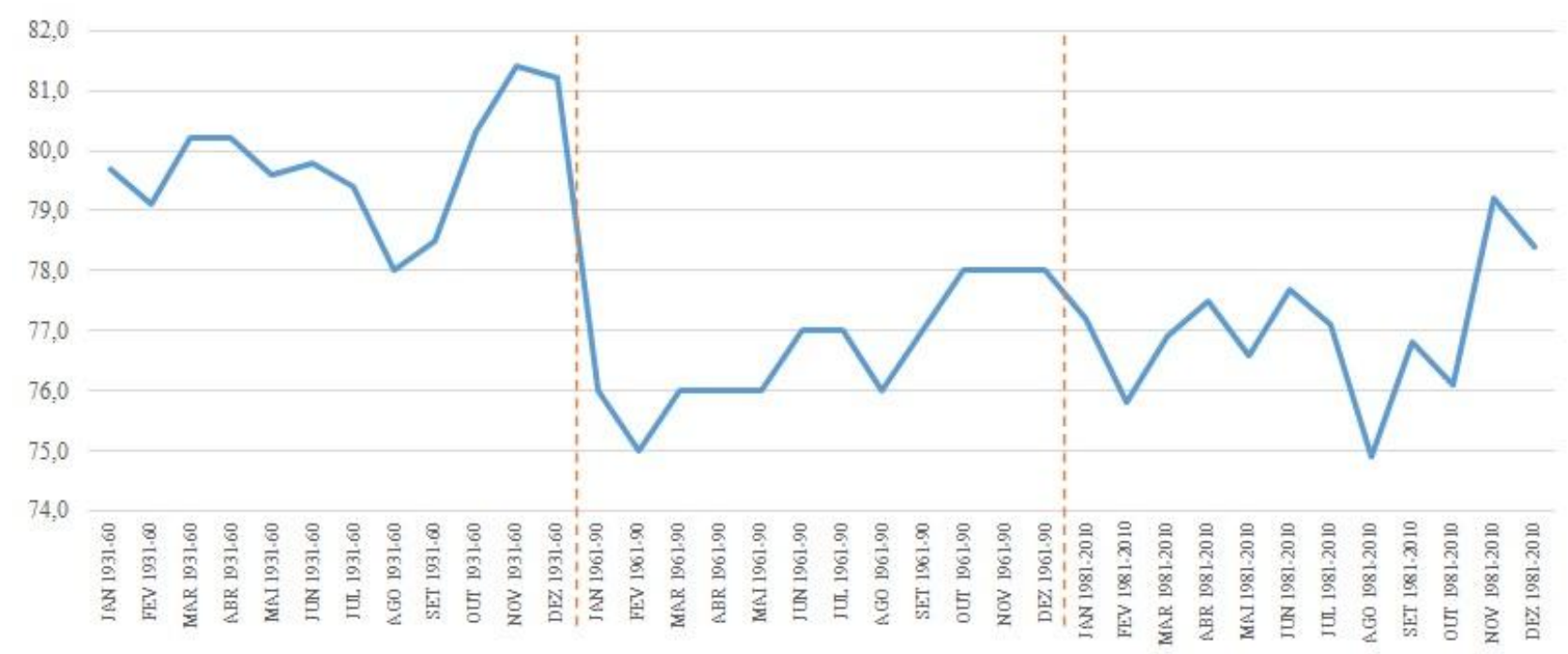

Figura 7: Gráfico Umidade Relativa do ar das Normais Climatológicas dos três períodos analisados. Fonte: Adaptado do Inmet (2020a e 2020b) e Autores (2020).

Fatores de ordem geoambiental como relevo e hipsometria não sofreram alterações importantes ao longo do tempo capazes de influenciar na dinâmica climática do município. Já os sistemas atmosféricos, que 
também contribuem fortemente na caracterização climática local, não foram possíveis de serem analisados na série histórica.

A forte urbanização, o adensamento e a verticalização que ocorreram a partir dos anos de 1990 estão interligados com as maiores diferenças de TE, que se apresentaram justamente entre 1961-1990 e 1981-2010. Mesmo havendo um intervalo de dez anos comum entre os períodos, ou seja, pouco mais de 30,0\% de dados equivalentes, os períodos possuem uma grande diferença na média mensal, indicando, no mínimo, um acréscimo de $0,4^{\circ} \mathrm{C}$ na temperatura do ar nos meses de agosto e setembro. Em relação à sensação de conforto térmico pelo índice TE o menor aumento verificado é de $0,3^{\circ} \mathrm{C}$ no mês de agosto.

De acordo com o Painel Brasileiro de Mudanças Climáticas (PBMC, 2014), para que os resultados alcançados em análises, independente da metodologia utilizada, possam ser conclusivos e indicativos de mudanças climáticas, as séries de observação analisadas não podem ser curtas, sendo necessário avaliar pelo menos um século, porém muitas vezes não é possível por não existirem dados, o que é o caso de Vitória. As transformações verificadas no comportamento da temperatura de Vitória, no período analisado, revelam uma tendência de aumento compatível com as indicações feitas no relatório do IPCC, porém ainda apresentam valores um pouco mais altos, ressaltando a preocupação com o desenvolvimento urbano local. Marengo (2007) relata que, quando as tendências apresentam valores altos, as mesmas não podem ser relacionadas apenas à variabilidade natural, devendo ser atribuídas também ao efeito antropogênico, juntamente com o crescimento das cidades.

\section{Considerações finais}

As séries estudadas evidenciam uma tendência climática de Vitória, a partir da análise dos valores de temperatura e do índice de Temperatura Efetiva (TE). A ascendente evolução urbana a partir do século XX modificou o espaço natural, alterando a cobertura do solo, os materiais e até mesmo o contorno da cidade e seu limite com o mar, influenciando nas características da atmosfera local.

Os elementos da atmosfera na cidade de Vitória, em especial a temperatura, sofreram transformações à medida que a cidade se desenvolvia, e ainda se desenvolve. $\mathrm{O}$ aumento gradativo da temperatura do ar e a diminuição da umidade acarretam maior desconforto térmico com o passar dos anos, podendo afetar diretamente na qualidade de vida da população e no consumo de energia.

Cabe ressaltar que a análise feita com base nas normais climatológicas do INMET se dá a partir das médias mensais, quer dizer, não avalia o comportamento diário com sua amplitude térmica, o que significa que em uma avaliação detalhada dos períodos do dia seriam obtidas sensações térmicas com valores mais altos, apresentando maior desconforto e, como resultado, requisitando maior esforço do sistema termorregulador para preservar a temperatura interna do corpo. Recomenda-se para estudo futuro a avaliação dos extremos de temperatura, ou seja, da tendência da temperatura mínima e da temperatura máxima.

A avaliação feita se mostrou eficaz para a verificação do conforto térmico ao longo da evolução urbana de Vitória, assim sendo, entende-se que as evidências encontradas quantificam de forma geral o impacto nas condições climáticas de Vitória, agravado pelo desenvolvimento da cidade. Além do mais, acentua a necessidade do planejamento urbano considerando fatores ambientais e climáticos, a fim de estudar medidas para mitigar os possíveis efeitos das mudanças climáticas sejam eles provenientes de variações naturais ou antrópicas.

\section{Referências}

BACK, Á. J.; OLIVEIRA, T. DE S. A urbanização e as modificações do clima. In: Gonçalves, T. M.; Santos, R. dos (Org.). Cidade e meio ambiente: estudos interdisciplinares. Criciúma- SC: Ed. UNESC, p. 207-228, 2010.

BARATA, M. M. L.; BADER, D. A.; DERECZYNSKI, C.; REGOTO, P.; ROSENZWEIG, C. Use of Climate Change Projections for Resilience Planning in Rio de Janeiro, Brazil. Frontiers in Sustainable Cities. London, v. 2, n. 28. 2020. https://doi.org/10.3389/frsc.2020.00028

BLAKE, R.; GRIMM, A.; ICHINOSE, R.; HORTON, R.; GAFFIN, S.; JIONG, S.; BADER, D.; CECIL, L. D. Urban climate: Processes, trends, and projections. In: Climate Change and Cities: First Assessment Report of the Urban Climate Change Research Network [Rosenzweig, C., W.D. Solecki, S.A. Hammer, e S. Mehrotra (Eds.)], Cambridge University Press, Cambridge, UK, 309 pp., p. 43-81., 2011. 
BRAGA, R. Planejamento urbano e mitigação da mudança do clima: análise da contribuição do plano diretor de desenvolvimento de Piracicaba - SP. In: ENCONTRO NACIONAL DE POS-GRADUAÇÃO EM GEOGRAFIA-ENANPEGE, 13, Anais..., São Paulo-SP. $2019 . \quad$ Disponível em $<$ https://www.enanpege2019.anpege.ggf.br/resources/anais/8/1562463517_ARQUIVO_Artigoenanpegefinal. pdf >. Acesso em: 02 dez. 2020.

CASTIGLIONI, A. H. Processo de crescimento da Grande Vitória. Revista Instituto Jones. Vitória-ES, ano VII, n. 1, 1994.

COCCOLO, S.; KÄMPF, J.; SCARTEZZINI, J. L.; PEARLMUTTER, D. Outdoor human comfort and thermal stress: A comprehensive review on models and standards. Urban Climate, New York, v. 18, p. 3357, 2016.

COELHO, A. L. N. Distribuição das Classes de Temperatura de Superfície a partir da faixa do infravermelho termal do Sensor TM/Landsat-5 no Município de Vitória (ES). In: SIMPOSIO BRASILEIRO DE SENSORIAMENTO REMOTO, 16, Anais..., Foz do Iguaçu-PR. 2013. Disponível em <http://marte2.sid.inpe.br/col/dpi.inpe.br/marte2/2013/05.28.23.11.34/doc/p0257.pdf >. Acesso em: 5 jun. 2020.

COELHO, A. L. N.; CORREA, W. S. C. Temperatura de superfície celsius do sensor tirs/landsat-8: metodologia e aplicações surface temperature sensor tirs/landsat-8. Revista Geográfica acadêmica. Goiânia-GO v. 7, n. 1, p. 31-45, 2013. Disponível em <https://revista.ufrr.br/rga/article/view/2996/1733>. Acesso em: 5 jun. 2020.

CORREA, W. S. C. Comportamento dos elementos climáticos, temperatura e precipitação, no município de Vitória (ES) no período de 1978 a 2007. 83f. 2011. Dissertação (Mestrado em Geografia). Centro de Ciências Humanas e Naturais. Departamento de Geografia. Universidade Federal do Espírito Santo. Disponível em $\langle$ http://www.geo.ufes.br/sites/geografia.ufes.br/files/field/anexo/Wesley.pdf $\rangle$. Acesso em: 5 jun. 2020.

CORREA, W. S. C.; VALE, C. C. Contribuição à compreensão do campo térmico da regional praia do canto, em vitória (es) pela metodologia de transectos. Revista Ra'ega, Curitiba-PR, v. 38, n. 1, p. 50-81, 2016. http://dx.doi.org/10.5380/raega.v38i0.41854

CORREA, W. S. C.; COELHO, A. L. N.; VALE, C. C. Influência de distintos sistemas atmosféricos na temperatura de superfície do município de Vitória (ES). Caminhos de Geografia, Uberlândia-MG, v. 16, n. 53, p. 37-54, 2015. Disponível em 〈http://www.seer.ufu.br/index.php/caminhosdegeografia/article/view/26984>. Acesso em: 5 jun. 2020.

CORREA, W. S. C. Impacto da alteração da superfície na circulação atmosférica da região metropolitana da Grande Vitória (ES). 243f. 2020. Tese (Doutorado em Geografia). Centro de Ciências Humanas e Naturais. Programa de Pós Graduação em Geografia da Universidade Federal do Espírito Santo. Disponível em 〈http://portais4.ufes.br/posgrad/teses/tese_14417_Tese_WESLEY_VFinal.pdf>. Acesso em: 23 jun. 2020.

DUARTE, D. H. S. Padrões de ocupação do solo e microclimas urbanos na região de clima tropical continental. 2000. 278f. Tese (Doutorado em Arquitetura e Urbanismo) - Universidade de São Paulo. Faculdade de Arquitetura e Urbanismo. São Paulo, 2000.

FANGER, P.O. Thermal comfort: Analysis and applications in environmental engineering. McGraw-Hill Book Company, New York, 1972.

FANTE, K.; DUBREUIL, V.; SANTA'ANNA NETO, J. L. Avaliação comparativa entre metodologias de identificação de situações de conforto térmico humano aplicado ao contexto tropical, Presidente Prudente/Brasil. Revista Brasileira de Climatologia, Curitiba-PR, Ano 13, v. 21, p. 588-612, jul/dez 2017. http://dx.doi.org/10.5380/abclima.v21i0.53839

FREIRE, A. L. O. Projetos de urbanização em Vitória-ES: aspectos do processo de produção de uma metrópole moderna. GEOUSP - Espaço e Tempo, São Paulo-SP, n. 15, p. 105-117, 2004. 
FREITAS, J. F. B. Aterros e decisões políticas no município de Vitória: efeito cascata. In: SEMINÁRIO DE HISTÓRIA DA CIDADE E DO URBANISMO, 8, Anais..., Niterói: ARQ.URB/UFF, PPGG/GEO/UFRJ, IPPUR/UFRJ e PROURB/FAU/UFRJ, 2004. v. 1. p. 1 - 17.

FROTA, A. B.; SCHIFFER, S. R. Manual de conforto térmico: arquitetura e urbanismo. 7.ed. São Paulo: Studio Nobel, 2003.

GIGUERE, M. Mesures de lutte aux îlots de chaleur urbains. Institut national de santé publique du Québec, Direction des risques biologiques, environnementaux et occupationnels, 95p. 2009.

GIVONI, B. Climate considerations in building and urban design. John Wiley \& Sons, Inc., New York, 1998.

GOLANY, G. S. Urban design morphology and thermal performance. Atmospheric Environment, London, v. 30, n. 3, p. 455-465, 1996.

GOMES, W. P. Características da temperatura na zona costeira: análise do clima urbano em UbatubaSP. 209f. Dissertação (Mestrado em Geografia). Programa de Pós-Graduação em Geografia da Faculdade de Ciências e Tecnologia da, Universidade Estadual Paulista "Julio de Mesquita Filho" - FCT/UNESP - campus de Presidente Prudente, Presidente Prudente, 2017.

GOOGLE. Software Google Earth 7. Estados Unidos, 2013. Disponível em <http://www.google.pt/earth/>. Acesso em: 23 mai. 2020.

IBGE. Instituto Brasileiro de Geografia e Estatística. Disponível em <https://mapas.ibge.gov.br/bases-ereferenciais/bases-cartograficas/malhas-digitais>. Acesso em: 3 abr. 2020.

INMET. Instituto Nacional de Meteorologia: Gráficos Climatológicos. Disponível em <http://www.inmet.gov.br/portal/index.php?r=clima/graficosClimaticos>. Acesso em: 16 mar. 2020a.

INMET. Instituto Nacional de Meteorologia: Normais Climatológicas do Brasil. Disponível em <http://www.inmet.gov.br/portal/index.php?r=clima/normaisClimatologicas〉. Acesso em: 16 mar. $2020 \mathrm{~b}$.

INSTITUTO DE APOIO À PESQUISA E AO DESENVOLVIMENTO JONES DOS SANTOS NEVESIPES. Verticalização e reestruturação urbana na região metropolitana da grande vitória 1990-2002. Vitória, $1997 . \quad$ Vitória, 2005.238 . 20 Disponível 〈http://www.ijsn.es.gov.br/component/attachments/download/137〉. Acesso em: 20 jun. 2020.

IPCC - Intergovernmental Panel on Climate Change: Climate Change 2014: Synthesis Report. Contribution of Working Groups I, II and III to the Fifth Assessment Report of the Intergovernmental Panel on Climate Change. IPCC, Geneva, Switzerland, 2014. 151p.

IPEA. Instituto de Pesquisa Econômica Aplicada. População residente - total. Disponível em <http://www.ipeadata.gov.br/Default.aspx>. Acesso em: 15 nov. 2020.

JESUS, R. J.; COELHO, A. L. N. Análise do campo térmico do município de Vitória através de produtos Landsat-8/TIRS/OLI. In: SIMPOSIO BRASILEIRO DE SENSORIAMENTO REMOTO, 17, Anais..., João Pessoa-PB. 2015. Disponível em <http://www.dsr.inpe.br/sbsr2015/files/p0908.pdf>. Acesso em: 5 jun. 2020.

JESUS, R. J. Avaliação do comportamento da temperatura da superfície terrestre do município de Cariacica (es) em 1985 e 2013. 176f. 2016. Dissertação (Mestrado em Geografia). Centro de Ciências Humanas e Naturais. Programa de Pós Graduação em Geografia da Universidade Federal do Espírito Santo. Disponível em: <http://portais4.ufes.br/posgrad/teses/tese_10000_RAFAEL\%20JUSTINO\%20DE\%20JESUS20161123143752.pdf $>$. Acesso em: 13 jun. 2020.

KOTTEK, M.; GRIESER, J.; BECK, C.; RUDOLF, B.; RUBEL, F. World Map of the Köppen-Geiger climate classification updated. Meteorologische Zeitschrift 15, p.259-263, 2006. 
LAMBERTS, R. Conforto e Stress térmico. Universidade Federal de Santa Catarina - Centro Tecnológico - Departamento de Engenharia Civil, 2011.

LAMBERTS, R.; GOULART, S. V. G.; DUTRA, S.; ANDRADE, L.; PEREIRA, FERNANDO, O. R.; BARBOSA, M. G. Building Bioclimatology in Brazil. In: INTERNATIONAL CONFERENCE ON PASSIVE AND LOW ENERGY ARCHITECTURE, 14, Proceedings... PLEA 97, Kushiro, Japan. p. 203208. 1997.

LANDSBERG, H. E. The urban climate. New York: Academic Press, 1981.

LOMBARDO, M. A. Ilhas de calor nas metrópoles: o exemplo de São Paulo. São Paulo: Hucitec, 1985.

LORENA, R. B.; MARCHIORO, E.; HOLZ, S. Análise do campo térmico da área urbana do município de Vitória através de dados de sensoriamento remoto. In: SIMPOSIO BRASILEIRO DE SENSORIAMENTO REMOTO, 16, Anais..., Foz do Iguaçu-PR. 2013. Disponível em <http://marte2.sid.inpe.br/rep/dpi.inpe.br/marte2/2013/05.29.00.06.25>. Acesso em: 5 jun. 2020.

MACHADO, G. M. V.; JABOR, P. M.; COELHO, A. L. N.; ALBINO, J. Geohistorical evolution and the new geological map of the city of Vitoria, ES, Brazil. Ocean and Coastal Management, London, v. 151, p. 45-52, 2017. https://doi.org/10.1016/j.ocecoaman.2017.10.026

MARENGO, J. A. Mudanças climáticas globais e seus efeitos sobre a biodiversidade - caracterização do clima atual e definição das alterações climáticas para o território brasileiro ao longo do século XXI. Brasília: Brasília, 2007.

MARICATO, E. Dimensões da tragédia urbana. Revista comciencia, São Paulo-SP, 2002. Disponível em <http://www.comciencia.br/framebusca.htm>. Acesso em 2 jun. 2020.

MILLS, G. Urban climatology and urban design. In: INTERNATIONAL CONGRESS OF BIOMETEOROLOGY \& INTERNACIONAL CONFERENCE ON URBAN CLIMATOLOGY, 15, Proceedings..., Macquarke University, Sydney (Australia), p. 1-6, 1999.

MINC, C. A. Ecologia nos barrancos da cidade. In. Viana, G.; Silva, M.; Diniz, N. (Orgs). O desafio da sustentabilidade: Um debate socioambiental. São Paulo. Editora Perseu Abramo, 2001.

MISSENARD, A. L’Homme et le climat. Paris: Librairie Plon. 1937.

MONTEIRO, C. A. F. Teoria e Clima Urbano. In: MONTEIRO, C. A. F.; MENDONÇA F. de A. (ORG). Clima urbano, 2. ed., $2^{\circ}$ reimpressão. São Paulo: Contexto, 2015, p. $9-68$.

MONTEIRO, D. L.; COELHO, A. L. N. Sensoriamento Remoto Aplicado ao Mapeamento Termal: Uma análise espaço-temporal do Município de Serra (ES). In: SIMPOSIO BRASILEIRO DE SENSORIAMENTO REMOTO, 17, Anais..., João Pessoa-PB. 2015. Disponível em 〈http://www.dsr.inpe.br/sbsr2015/files/p0295.pdf $>$. Acesso em: 5 jun. 2020.

NEDEL, A. S.; GONÇALVES, F. L. T.; MACEDO JUNIOR, C.; CARDOSO, M. R. A. CLIMATOLOGY OF THE HUMAN THERMAL COMFORT ON SÃO PAULO METROPOLITAN AREA, BRAZIL: INDOORS AND OUTDOORS. Brazilian Journal of Geophysics, [S.1.], v. 33, n. 2, p. 185-204, jun. 2015. ISSN 1809-4511. http://dx.doi.org/10.22564/rbgf.v33i2.713

OKE, T. R. Boundary Layer Climates. 2.ed. London: Routledge, 2002, 1987.

OLIVEIRA, W. D. O campo térmico do distrito de Carapina - Serra/ES: estudo de caso em áreas litorâneas. 220f. 2018. Dissertação (Mestrado em Geografia). Centro de Ciências Humanas e Naturais. Programa de Pós Graduação em Geografia da Universidade Federal do Espírito Santo. Disponível em $<$ http://repositorio.ufes.br/jspui/handle/10/10886>. Acesso em: 23 jun. 2020. 
PAIVA, J. P. M. Análise microclimática em conjuntos Habitacionais: o caso do conjunto Ceará Fortaleza/CE. Dissertação (Mestrado em Geografia) - Universidade Estadual do Ceará, Centro de Ciências e Tecnologia. Fortaleza, 2010. 156 f. Disponível em <http://www.uece.br/mag/dmdocuments/joao paulo dissertaçao.pdf >. Acesso em: 10 jan 2012.

PAULA, M. L. M. Comparação do campo térmico da SUC do município de Vitória - ES, em relação às alterações de uso e ocupação do solo urbano em 1991 e 2011. 79f. 2015. Dissertação (Mestrado em Geografia). Centro de Ciências Humanas e Naturais. Departamento de Geografia. Universidade Federal do Espírito Santor Disponível em 〈http://geografia.ufes.br/sites/geografia.ufes.br/files/field/anexo/tcc_corrigido_luiza.pdf $\rangle$. Acesso em: 5 jun. 2020.

PBMC - Painel Brasileiro de Mudanças Climáticas: Base científica das mudanças climáticas. Contribuição do Grupo de Trabalho 1 do Painel Brasileiro de Mudanças Climáticas ao Primeiro Relatório da Avaliação Nacional sobre Mudanças Climáticas. COPPE. Universidade Federal do Rio de Janeiro, Rio de Janeiro, RJ, Brasil, 2014. 464 p.

PEREIRA, A. S.; ROCHA, D. S. Análise da temperatura superficial terrestre do município de Serra - ES, a partir de imagem orbital do Sensor OLI/Landsat-8. In: SIMPOSIO BRASILEIRO DE SENSORIAMENTO REMOTO, 19, Anais..., Santos-SP. $2019 . \quad$ Disponível <http://marte2.sid.inpe.br/col/sid.inpe.br/marte2/2019/10.31.11.34/doc/97982.pdf $\geq$. Acesso em: 5 jun. 2020.

PMV. Prefeitura Municipal de Vitória: Dados Geográficos. Disponível em <http://legado.vitoria.es.gov.br/regionais/geral/geograficos.asp>. Acesso em: 30 mar. 2020a.

PMV. Prefeitura Municipal de Vitória: Evolução Urbana. Disponível em <https://www.vitoria.es.gov.br/cidade/evolucao-urbana>. Acesso em: 30 mar. 2020b.

PMV. Prefeitura Municipal de Vitória: Memória Visual Baía de Vitória. Disponível em <http://legado.vitoria.es.gov.br/baiadevitoria/>. Acesso em: 30 mar. 2020c.

ROLNIK, R.; KLINK, J. Crescimento econômico e desenvolvimento urbano: por que nossas cidades continuam tão precárias?. Novos estudos - CEBRAP, São Paulo-SP, n. 89, p. 89-109, 2011. Disponível em <https://www.scielo.br/scielo.php?pid=S0101-33002011000100006\&script=sci_arttext. $>$. Acesso 2 jun. 2020.

ROUX, J. L'îlot de Chaleur Urbain à Dijon: Mise en place d'une campagne de mesures urbaines de la température. (Mémoire de Master - Dissertação de Mestrado), p. 93. UFR Sciences Humaines, Département de Géographie, Université de Bourgogne, Dijion, 2014.

SANT'ANNA NETO, J. L. Decálogo da climatologia do sudeste brasileiro. Revista Brasileira de Climatologia, Presidente Prudente-SP, v. 1, n. 1, p. 43-60, 2005. Disponível em <https://revistas.ufpr.br/revistaabclima/article/view/25232/16936>. Acesso em: 2 jun. 2020.

SILVA, L. S.; GAIGHER, B.; SILVA, D. G.; ROSA, L. O.; SILVA, R. A.; SOUSA, W. B. Análise comparativa dos campos térmicos do município de Vitória nas estações de inverno e verão através de dados de sensoriamento remoto. In: SIMPOSIO BRASILEIRO DE SENSORIAMENTO REMOTO, 18, Anais..., Santos-SP. 2017. Disponível em <https://proceedings.science/sbsr/papers/analise-comparativa-dos-campostermicos-do-municipio-de-vitoria-nas-estacoes-de-inverno-e-verao-atraves-de-dados-de-sens?lang=pt-br _ >. Acesso em: 5 jun. 2020.

SILVA, F. T.; SCARIONE, P.; ALVAREZ, C. E. A influência da rugosidade e porosidade da tipologia urbana na ventilação em área litorânea e a percepção de conforto do transeunte. In: ENCONTRO NACIONAL DE TECNOLOGIA DO AMBIENTE CONSTRUÍDO, 14, Anais..., Juiz de Fora. 2012. Disponível em 〈http://lpp.ufes.br/sites/lpp.ufes.br/files/field/anexo/artigo3498763.pdf〉. Acesso em: 5 jun. 2020.

SOUZA, D. M, NERY, J. T. O conforto térmico na perspectiva da climatologia geográfica. Geografia, Londrina-PR, v. 21, n. 2, p. 65-83, 2012. http://dx.doi.org/10.5433/2447-1747.2012v21n2p65 
SOUZA, S. M.; SILVA, A. G.; SANTOS, A. R.; GONÇALVES, E.; MENDONÇA, A. R. Análise dos fragmentos florestais urbanos da cidade de Vitória - ES. REVSBAU, Piracicaba - SP, v.8, n.1, p.112-124, 2013. http://dx.doi.org/10.5380/revsbau.v8i1.66348

VAREJÃO-SILVA, M. A. Meteorologia e climatologia. Recife, 2005.

(1) (5) (2)

BY 